\title{
Can Hybrid Course Formats Increase Attendance in Undergraduate Environmental Science Courses?
}

\author{
Samuel K. Riffell** and Duncan F. Sibley
}

\begin{abstract}
A major problem for large-enrollment, introductory college courses in natural resources and life sciences is poor attendance. To ameliorate this problem, we designed a hybrid course (part online, part face-to-face) to incorporate the advantages of online learning while retaining benefits of face-to-face instruction. We taught a hybrid introductory college science course (containing online assignments) simultaneously with a traditional lecture course (containing passive lectures). Completion rates of online homework were greater than attendance rates to passive lectures, and this difference increased with higher class rank. Our results suggest that hybrid course formats might be effective for increasing student attendance, particularly upperclassmen, in introductory life sciences and natural resource courses.
\end{abstract}

M OST INTRODUCTORY COLLEGE COURSES in the natural resources and life sciences are large lecture courses (100 to $400+$ students). Introductory courses for science majors are foundational courses of the discipline. For nonscience majors, introductory courses fulfill general science requirements, and more importantly, often represent the only opportunity for these students to learn how the natural sciences inform and impact their own disciplines. Unfortunately, large introductory courses are usually poorly attended (Feldmann and Carney, 1998), and performance and learning suffer (Moore, 2003).

Since the advent of the World Wide Web and internet technology, web-based teaching methods have proliferated. Webbased learning environments may be more student-centered, interactive, and flexible than many traditional course formats, but they may also fail to provide adequate face-to-face interaction with instructors and classmates (Yazon et al., 2002). However, courses that combine both classroom and online activities (hybrid courses) have the potential to capture benefits of web-based environments while retaining benefits of traditional classroom environments. Because hybrid courses retain high-quality student-faculty interaction (Navarro and Shoemaker, 2000; Riffell and Sibley, 2003) while enhancing learning outcomes (Tuckman, 2002), they are becoming an increasingly popular option (Young, 2002).

We developed a hybrid course to improve the low attendance of resident students in large, introductory science courses at Michigan State University. These introductory courses are offered through the Center for Integrative Studies, and they satisfy general science requirements for a wide variety of nonscience majors. We hypothesized that students

S.K. Riffell, Dep. of Zoology, 203 Natural Science Building, Michigan State Univ., East Lansing, MI 48824; and D.F. Sibley, Dep. of Geological Science and Center for Integrative Studies-General Science, Michigan State Univ., East Lansing, MI 48824. Received 15 May 2003. *Corresponding author (sriffell@cfr.msstate.edu).

Published in J. Nat. Resour. Life Sci. Educ. 33:16-20 (2004). http://www.JNRLSE.org

(C) American Society of Agronomy

677 S. Segoe Rd., Madison, WI 53711 USA would be more likely to "attend" online activities (attendance defined as attempting at least half the problems in an online assignment) compared with passive classroom lectures for two reasons. First, web-based technology is an increasingly familiar environment for undergraduates. Second, students may be more likely to "attend" class activities when they have more control over the time and place they participate (i.e., online assignments) compared with passive lectures, which must be attended at set times and places (St. Clair, 1999; Friedman et al., 2001). Because we wanted to avoid the pitfalls associated with wholly online courses, we retained 1 hour per week of faceto-face instruction.

To evaluate the impact of the hybrid course format, we compared attendance rates in a traditional, lecture-based environmental biology course and a hybrid version of the same course. Evaluation of online learning has focused on either student perceptions and/or academic performance of students (Dewhurst et al., 2000; King and Hildreth, 2001; Tuckman, 2002; Yazon et al., 2002; and many others), but the effects of hybrid course environments on foundational outcomes such as class attendance in higher education have not been reported. Understanding the effects of hybrid course formats on attendance rates is important because attendance rates have been repeatedly demonstrated to predict academic performance (Launius, 1997; Gatherer and Manning, 1998; Moore, 2003). If hybrid environments can improve attendance rates, then instructors could have an effective tool for increasing attendance and consequently, performance in poorly attended courses in natural resources and life sciences programs.

\section{DESCRIPTION OF THE HYBRID COURSE}

Our course, Applications of Environmental Biology, focused on applications of basic biological (e.g., photosynthesis, logistic population growth), ecological (e.g., energy flow, predator-prey interactions), and sociological processes (e.g., economic growth) to understanding major environmental issues (e.g., global warming and forest management). The hybrid course incorporated two primary components. First, active lectures met once per week in the lecture hall, and focused on cooperative, group activities for learning core skills and concepts. Second, online assignments were biweekly, webbased homework problem sets. Each week of the course, one online assignment was due the night before the active-learning lecture (Fig. 1). A second online assignment, due several days after the active lecture, reinforced and extended concepts dealt with in class.

\section{Active Lectures}

We structured our weekly meetings around active-learning exercises because active-learning increases student attention and concept retention (Ebert-May et al., 1997; Springer et al., 1999). The instructor lectured for a short period (5-15 minutes) and then presented a problem for students to complete. 
Groups were informal (i.e., not assigned by the instructor) and students generally worked with their nearest neighbors. In addition to peers, students could ask questions of the instructor and teaching aide. When the problem was completed, each student turned in their own answer to be graded on machinescored bubble sheets. The instructor summarized the activity through another short lecture period (5-15 minutes). In a single 50-minute class session, one or two exercises were completed. A more detailed description of these lessons and example activities are in Riffell and Sibley (2003).

\section{Online Assignments}

We replaced two-thirds of the time traditionally spent in lecture with online assignments (approximately 50 questions per week). Questions were designed to encourage reading the text for content, comprehension of major processes, and applications. Each assignment contained a mixture of multiple choice, matching, true/false, and calculation problems (Riffell and Sibley, 2003 contains example problems). Generally, online assignments (i) provide students with more flexibility and control over where and when to participate (Ostiguy and Haffer, 2001), (ii) are less passive than taking notes in lecture (Hacker and Niederhauser, 2000), (iii) are more studentcentered (Sanders, 2001), and (iv) encourage students to learn in different ways (Yazon et al., 2002).

We used an early version of the open-source, web-based platform LON-CAPA (visit the software website at www.loncapa.org; verified 16 Jan. 2004) to deliver our online assignments. Specific features of LON-CAPA are critical to our hybrid design (Speier and Kortemeyer, 2001). First, questions are individualized so that each student received a slightly different version of each question (e.g., different choices or different starting numbers for calculations) based on a random number algorithm. Individualized online assignments encouraged students to work together, but prevented students from simply copying another student's answers. Second, students received three attempts to get full credit and received partial credit after three attempts. Multiple attempts to get full credit encouraged mastery of the content. Third, LON-CAPA provided feedback to students through pre-programmed hints received after incorrect answers and through a mechanism to contact the instructor with questions about specific problems.

\section{METHODS}

\section{Experimental Design}

In spring of 2002, we taught the hybrid course concurrently with a traditional version of the course. The traditional course included the same subject matter as the hybrid course and was taught by the same instructor. The traditional course retained the active-learning lectures, but subject matter covered in online assignments in the hybrid course was covered using passive lectures instead (Fig. 1). Lectures in the traditional course were passive in that the instructor did not provide activelearning exercises or group work during these times and did not directly query students. However, the instructor did use multiple forms of media (PowerPoint, VHS) and answered student questions during class.

Students were self-selected (i.e., enrollment was open for both courses), but neither class was aware of the nature of the research experiment. Because students were self-selected, we also measured the following characteristics to see if the two groups were different in ways that might affect attendance patterns: percentage male, percentage freshman, percentage fulltime students, percentage commuter students; percentage that had previously taken an online course, and percentage that had previously taken an ISB course at Michigan State University. The only characteristic that differed significantly ( $\chi^{2}$ test, $\alpha$ $<0.05$ ) was percentage freshman (hybrid course $=30 \%$ freshman, traditional course $=46 \%$ freshman).

\section{Active Lecture Attendance Rates}

Because students turned in graded exercises during each active-learning lecture, we calculated active-learning lecture attendance rates as the percent of exercises turned in by each student.

\section{Passive Lecture Attendance vs. Online Assignment "Attendance"}

To record passive lecture attendance rates (traditional course only), students passed their identification card through an electric card reader mounted in the lecture hall when entering and exiting class. We calculated passive lecture attendance rates as the percentage of lectures for which students were present.
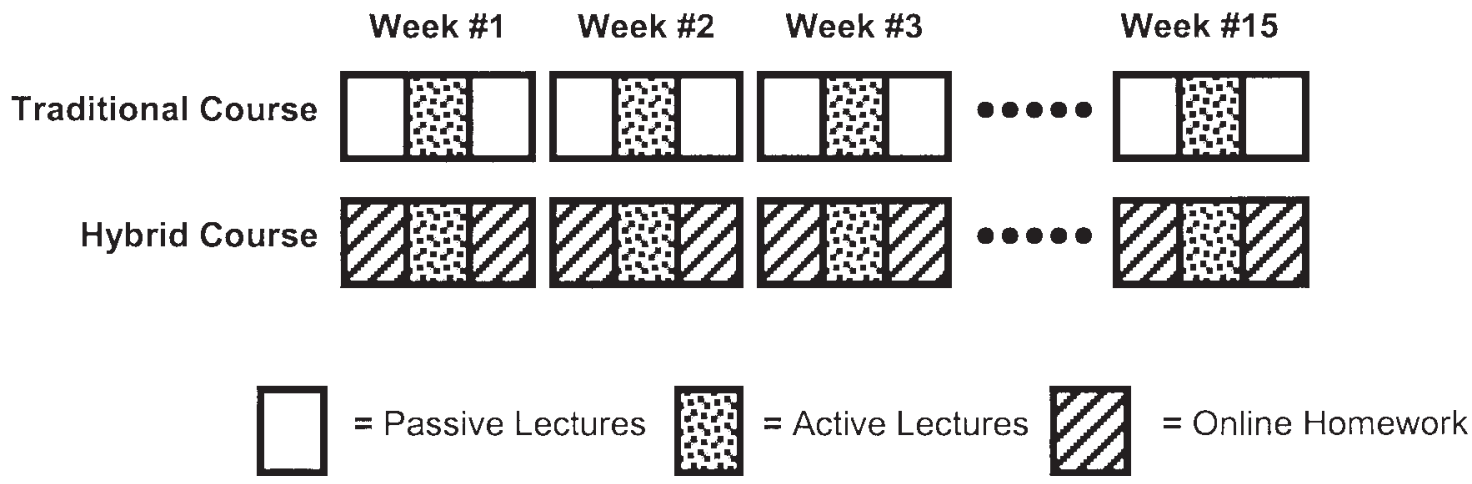

Fig. 1. Experimental design involving the hybrid and traditional formats of the introductory, environmental biology course. Each rectangle represents one 50-minute instructional period (passive lecture, active lecture, or online assignment), and each set of three represents a unit (a week) of the course. 
In the hybrid course, students completed two assignments per week in lieu of lecture time. To measure online assignment "attendance" rates, we considered a student to have "attended" an assignment if half of the homework problems for that assignment had been attempted. This measure is equivalent to passive lecture attendance rates because a students' attention in passive lectures varies (e.g., wandering thoughts, sleeping, studying other subjects, etc.), and only a portion of the information may be assimilated in some lectures even though the student is physically present the entire time (Cooper and Robinson, 2000).

Students in both the traditional course and the hybrid course had similar grade incentives to attend lectures or complete assignments (students could get full credit with approximately $80 \%$ compliance). Passive lecture attendance comprised $17 \%$ of each student's final grade in the traditional course, and was awarded based on the following scale: attend $80 \%$ of the lectures $=17 \%$; attend $70 \%$ of the lectures $=15 \%$; attend $60 \%$ of the lectures $=12 \%$; and so forth. In the hybrid course, completion percentages [(Points earned / Total points assigned $\times 100$ ] of online assignments counted as $15 \%$ of each student's final grade. However, we also provided several bonus online assignments so students could miss approximately $20 \%$ of the regular assignments and still recoup those points.

\section{Statistical Analysis}

We hypothesized that (i) active lecture attendance rates would be higher when coupled with online assignments (hybrid course) than when coupled with passive lectures (traditional course); and (ii) that online assignment "attendance" rates (hybrid course) would be higher than passive lecture attendance rates (traditional course). Although we stated hypotheses that could be one-tailed, we used more conservative two-tailed tests to retain the ability to detect effects that were in the opposite direction. Because our data often violated assumptions of the parametric $t$-test (i.e., unequal variance, nonnormality), we used Wilcoxon's two-sample test (Sokal and Rohlf, 1995). Because $n<20$ for some of our individual com-

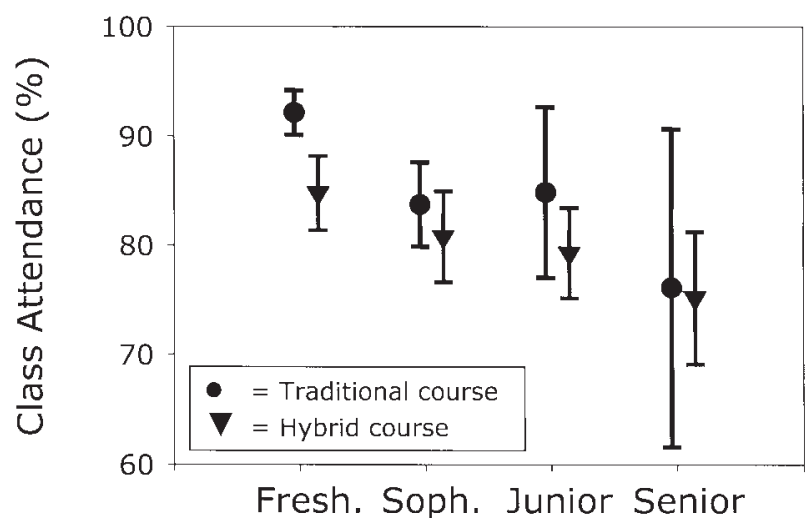

Fig. 2. Active-learning lecture attendance in the hybrid vs. the traditional course by class rank (mean $\pm 1 \mathrm{SE}$ ). Only the comparison for the freshmen was significant after a Bonferroni correction (Hochberg, 1988). Sample sizes for the traditional course were: freshman (47); sophomore (35); junior (10); senior (9). Sample sizes for the hybrid course were: freshman (25); sophomore (25); junior (16); senior (17). parisons (Sokal and Rohlf, 1995), we used the MC option of the EXACT statement in SAS Proc NPAR1WAY to calculate exact $P$ values for each test (SAS Inst., 1999).

Because the hybrid course contained a lower percentage of freshman students (see Experimental Design above), we tested these hypotheses for all students as a group and for four types of students: freshmen, sophomores, juniors, and seniors. We treated each group of five hypothesis tests as a family (Westfall et al., 1999), and applied a sequential Bonferroni adjustment (Hochberg, 1988; Westfall et al., 1999) to avoid increased Type I error rates that can occur in groups of related hypotheses. We used an a priori, family-wide $\alpha=0.05$ for all tests.

\section{RESULTS}

\section{Active Lecture Attendance Rates}

For all students as a group, active-lecture attendance rates were $88 \%$ in the traditional course and $81 \%$ in the hybrid course $\left(T=6428.5 ; \mathrm{n}_{1}=101 ; \mathrm{n}_{2}=84 ; P<0.0001\right)$. Activelecture attendance rates were significantly lower in the hybrid course for freshmen $\left(T=703.0 ; \mathrm{n}_{1}=47 ; \mathrm{n}_{2}=25 ; P<0.0075\right)$, but there were no significant differences for sophomores, juniors, or seniors $(P=0.1022$ to 0.2774$)$. In both courses, active-lecture attendance rates also decreased with higher class rank (Fig. 2).

\section{Passive Lecture Attendance vs. Online Assignment "Attendance"}

For all students as a group, passive-lecture attendance rates (traditional course) were $78 \%$ while online homework "attendance" rates (hybrid course) were 93\% ( $T=10580.0 ; \mathrm{n}_{1}=$ $\left.101 ; \mathrm{n}_{2}=84 ; P<0.0001\right)$. Additionally, online homework "attendance" rates were significantly higher for freshman, sophomores, juniors, and seniors $(P=0.0001$ to 0.007$)$. Just like active-learning lecture attendance rates, passive-lecture attendance rates declined with higher class rank, but online homework "attendance" rates did not decline with higher class rank (Fig. 3).

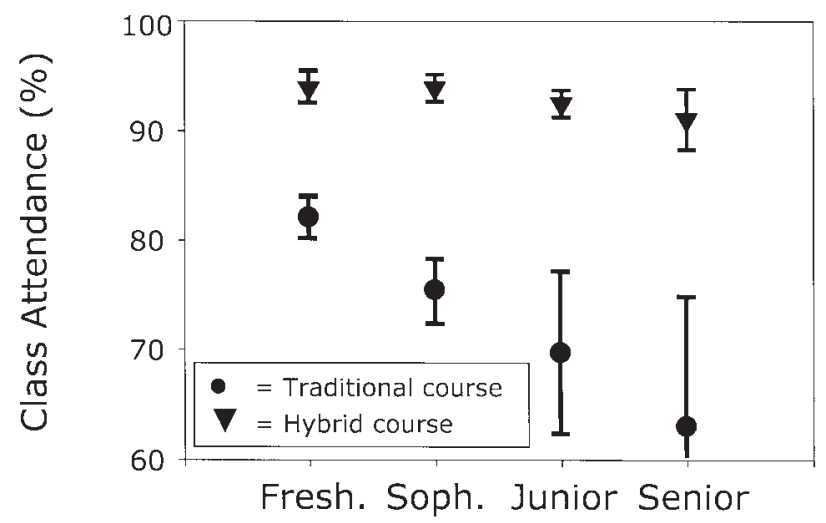

Fig. 3. Passive lectures (traditional course) vs. online assignment "attendance" (hybrid course) by class rank (mean $\pm 1 \mathrm{SE}$ ). All four comparisons were significant after a Bonferroni correction (Hochberg, 1988). Sample sizes for the traditional course were: freshman (47); sophomore (35); junior (10); senior (9). Sample sizes for the hybrid course were: freshman (25); sophomore (25); junior (16); senior (17). 


\section{DISCUSSION}

\section{Active Lecture Attendance Rates}

Contrary to our first hypothesis, active-learning lecture attendance rates were not higher when coupled with online assignments (hybrid course), and were significantly lower for freshman (Fig. 2). One of our goals in developing a hybrid class was to maintain the face-to-face interaction and incentive that is often necessary to academic success of freshman. Although the active-learning lecture attendance rates we observed in the hybrid course (84\%) were still very high compared with similar courses at Michigan State University, these results indicate that even reductions in the typical frequency of face-to-face interaction (three times per week) may have small, negative impacts on the attendance of freshman students.

We also observed a striking pattern: active lecture attendance rates decreased with increasing class rank in both courses. Because our hybrid course was a general education requirement, students who delay taking these requirements (i.e., juniors and seniors) may be more likely to view them as unnecessary and place a low priority on attendance. Another possibility is that students may be more motivated to attend class when they have more control over the learning environment (St. Clair, 1999; Freidman et al., 2001). Because upperclassmen should be more self-disciplined than freshmen, they may be more strongly motivated by control than underclassmen. Thus, they may be more likely to miss classes where they do not have control over meeting times and places. These trends are disconcerting because the intent of general education science classes is to provide students with a broad educational background and the ability to see the application of life sciences to their respective majors and ultimately to their careers. Students who delay taking these courses may not receive the necessary literacy in science to meet these objectives if their level of attendance and participation is low.

\section{Passive Lecture Attendance vs. Online Assignment "Attendance"}

Consistent with our second hypothesis, online assignment "attendance" rates were significantly higher than passive lecture attendance rates for freshmen through seniors. Passive lecture attendance rates also declined with increasing class rank (Fig. 3). Upperclassmen who delayed taking this general education requirement were less likely to place a high priority on attending passive lectures. This is consistent with patterns of attendance we observed for the active-learning lectures in both courses.

This trend, however, was not apparent in online assignment "attendance" rates. Upperclassmen were just as likely to complete online assignments as were freshmen (Fig. 3). Again, because upperclassmen may be more self-disciplined than freshmen, they may value class formats (like hybrids) that give them more control (St. Clair, 1999). This preference would manifest as a preference for "attending" online assignments and a tendency to miss lectures that meet at set times and offer little control or choice to the student. We observed both in our study. Hybrid course formats may be a valuable tool for improving the impact of general education courses when students postpone enrolling in these courses past their freshman year.

\section{CONCLUSIONS}

Although increasing attendance may not be a lofty goal, like improving critical thinking skills or increasing knowledge, it is nonetheless a basic and essential goal that undergraduate courses in life sciences and natural resources must achieve. The link between attendance and student performance is wellestablished (e.g. Moore, 2003), and clearly students cannot learn if they do not attend class or complete assignments. Our experiment suggests that hybrid course formats may help achieve these goals because students (especially upperclassmen) are more likely to complete online assignments compared with attending passive lectures. Most of the time, increased attendance should result in better learning gains.

Our results also highlighted the importance of class rank. Upperclassmen were less likely to attend both active-learning lectures and passive lectures compared with their freshmen counterparts, but were just as likely to complete online assignments. Providing more control over their learning environment through hybrid formats may be a superior alternative for upperclassmen taking introductory or general education courses in natural resources or life sciences. In contrast, attendance rates of freshmen to active-learning lectures were lower when coupled with online assignments (hybrid course) rather than passive lectures (traditional course). This underscored the importance of face-to-face interaction to freshman academic success.

Our results suggest that, for many courses and student audiences, hybrid courses represent an improvement over traditional lecture formats because they encourage students to attend class more regularly. Instructors of large, introductory courses could improve attendance (and hence, student performance and learning) by adopting similar hybrid formats. However, our results highlight the complexity, not only of evaluating the effectiveness of hybrid courses, but also of identifying the appropriate student groups for which hybrid formats are most appropriate. Instructors should carefully consider the intended student target when developing hybrid formats, and should conduct pilot assessments (Riffell and Sibley, 2003) when hybrid courses are implemented.

\section{ACKNOWLEDGMENTS}

D. Ebert-May, G. Kortemeyer, the members of the Research On Undergraduates Learning Science laboratory (ROULS) at Michigan State University, and an anonymous reviewer provided helpful comments on earlier versions of the manuscript.

\section{REFERENCES}

Cooper, J.L., and P. Robinson. 2000. The argument for making large classes seem small. New Directions for Teaching and Learning 81:5-16.

Dewhurst, D.G., H.A. Macleod, and T.A.M. Norris. 2000. Independent student learning aided by computers: An acceptable alternative to lectures? Comput. Educ. 35:223-241.

Ebert-May, D., C.A. Brewer, and S. Allred. 1997. Innovation in large lectures: Teaching for active learning through inquiry. BioScience 47:601-607.

Feldmann, R.M., and J.S. Carney. 1998. The effects of videotaping and attendance incentives to enhance performance in a high-enrollment oceanography course. J. Geosci. Educ. 46:330-336.

Freidman, P., F. Rodriguez, and J. McComb. 2001. Why students do and do not attend classes: Myths and realities. Coll. Teach. 49:124-133. 
Gatherer, D., and F.C.R. Manning. 1998. Correlation of examination performance with lecture attendance: A comparative study of first-year biological sciences undergraduates. Biochem. Educ. 26:121-131.

Hacker, D.J., and D.S. Niederhauser. 2000. Promoting deep and durable learning in the online classroom. New Directions for Teaching and Learning 84:53-64.

Hochberg, Y. 1988. A sharper Bonferroni procedure for multiple tests of significance. Biometrika 75:800-802.

King, P., and D. Hildreth. 2001. Internet courses: are they worth the effort. J. Coll. Sci. Teach. 31:112-115.

Launius, M.H. 1997. College student attendance: Attitudes and academic performance. Coll. Stud. J. 31:86-92.

Moore, R. 2003. Attendance and performance: How important is it for students to attend class? J. Coll. Sci. Teach. 32:367-371.

Navarro, P., and J. Shoemaker. 2000. Performance and perceptions of distance learners in cyberspace. Am. J. Distance Educ. 14:15-35.

Ostiguy, N., and A. Haffer. 2001. Assessing differences in instructional methods: Uncovering how students learn best. J. Coll. Sci. Teach. 30:370-374.

Riffell, S.K., and D.F. Sibley. 2003. Student perceptions of a hybrid learning format: Can online exercises replace traditional lectures? J. Coll. Sci. Teach. 32:394-399.

Sanders, W.B. 2001. Creating learning-centered courses for the world wide web. Allyn and Bacon, Boston, MA.

SAS Institute. 1999. SAS/STAT user's guide. Version 8. SAS Inst., Cary, NC.
Sokal, R.R., and F.J. Rohlf. 1995. Biometry. W.H. Freeman and Co., New York.

Speier, C., and G. Kortemeyer. 2001. Open source objects for teaching and learning. Syllabus Magazine. [Online.] Available at www.syllabus.com/article.asp?id=5671 (accessed 19 Dec. 2003; verified 16 Jan. 2004) 101communications, Chatsworth, CA.

Springer, L., M.E. Stanne, and S.S. Donovan. 1999. Effects of small-group learning on undergraduates in science, mathematics, engineering and technology: A meta-analysis. Rev. Educ. Res. 69:21-51.

St. Clair, K.L. 1999. A case against compulsory class attendance policies in higher education. Innov. Higher Educ. 23:171-180.

Tuckman, B.W. 2002. Evaluating ADAPT: A hybrid instructional model combining web-based and classroom components. Comput. Educ. 39:261-269.

Westfall, P.H., R.D. Tobias, D. Rom, R.D. Wolfinger, and Y. Hochberg. 1999. Multiple comparisons and multiple tests using the SAS System. SAS Inst., Cary, NC.

Yazon, J.M.O., J.A. Mayer-Smith, and R.J. Redfield. 2002. Does the medium change the message? The impact of a web-based genetics course on university students' perspectives on learning and teaching. Comput. Educ. 38:267-285

Young, J.R. 2002. 'Hybrid' teaching seeks to end the divide between traditional and online instruction. Chron. Higher Educ. 22 March. 